\title{
EFFECTS OF CARBIDES ON FATIGUE CHARACTERISTICS OF AUSTEMPERED DUCTILE IRON
}

\author{
B. Stokes ${ }^{1}$, N.Gao ${ }^{1}$, K.K. Lee ${ }^{2}$ and P. A. S. Reed ${ }^{1}$ \\ ${ }^{1}$ Materials Research Group, School of Engineering Sciences, University of \\ Southampton, Southampton, SO17 1BJ, UK \\ ${ }^{2}$ School of Computing Sciences, University of East Anglia, Norwich, NR4 7TJ
}

\begin{abstract}
Crack initiation and growth behaviour of an austempered ductile iron (ADI) austenitised at $800^{\circ} \mathrm{C}$ and austempered at $260^{\circ} \mathrm{C}$ has been assessed under three point bend fatigue conditions. Initiation sites have been identified as carbides remaining from the as cast ductile iron due to insufficient austenisation. The number of carbides cracking on loading to stresses greater than $275 \mathrm{MPa}$ is critical in determining the failure mechanism. In general, high carbide area fractions promote coalescence dominated fatigue crack failure whilst low area fractions promote propagation dominated fatigue crack failure. Individual carbides have been characterised using finite body tessellation (FBT) and adaptive numerical modelling (SUpport vector Parsimonious ANalysis Of VAriance (SUPANOVA)) techniques in an attempt to quantify the factors promoting carbide fracture. This indicated that large or long and thin carbides on the whole appear to be susceptible to fracture, and carbides that are locally clustered and aligned perpendicular to the tensile axis are particularly susceptible to fracture.
\end{abstract}




\section{INTRODUCTION}

Austempered ductile iron (ADI) is widely used in industry because it offers a combination of low cost, design flexibility, high strength-to-weight ratio and good toughness, wear resistance and fatigue strength ${ }^{[1,2,3]}$. Generally ADI alloys possess mechanical properties which are superior to conventional ductile iron and cast iron but comparable to heat treated forged steels. The microstructure is dependent on both the composition of the cast iron and the exact parameters of the four stages in the production process. The process comprises the production of a ductile iron casting, austenitisation $\left(800-950{ }^{\circ} \mathrm{C}\right)$, subsequent quenching to a temperature, $\left(250-400{ }^{\circ} \mathrm{C}\right)$, suitable for the final stage, the isothermal transformation (austempering) of some of the austenitic matrix to other phases, prior to subsequent cooling to room temperature. The austempering heat treatment, in addition to the austenitisation heat treatment, is of significance in determining the exact microstructure produced.

The camshaft is a critical component in a combustion engine and advanced engine designs. The high strength, good wear properties, castability and low cost of ADI make it particularly attractive for this application. However, due to a demand for improved engine performance, the service conditions for a camshaft have changed. This changes the demands placed on the camshaft material, requiring resistance to rolling (as oppose to sliding) fatigue resistance, and high strength and ductility. Contact fatigue is now a significant concern for manufacturers of this type of camshaft and it is clear that both wear and fretting fatigue play an important role. Fretting fatigue is a very situation-specific service problem, and the construction of appropriate tests is extremely complicated. Typically ${ }^{[4]}$ failure is due to the initiation and growth of very small cracks, which leads to surface pitting, resulting in further 
wear-induced failure. Therefore the study of initiation and early growth of cracks and the effect of various microstructural features of ADI on such growth is particularly important.

Building upon previous $\operatorname{work}^{[5,6,7]}$, this research further investigates the microstructure and related failure mechanisms of a specific ADI by conducting short and long fatigue crack testing, hardness testing and extensive image analysis. The objective of this research is to explicitly quantify the effects of local microstructural features on fatigue failure in this ADI material. Particular attention has been paid to characterisation of short fatigue crack initiation, early propagation and general fatigue crack growth behaviour. It is critical that a micro-mechanical understanding of the underlying early fatigue processes is developed to allow further development of quantitative performance optimisation criteria.

\section{EXPERIMENTAL PROCEDURE}

\section{A. Material Characterisation}

An ADI with composition: 3.7C-1.5Si-0.3Mn-1.0Cu-0.5Mo (all numbers are wt.\%) and balance Fe was supplied by Federal Mogul Camshafts as a sand cast block, which subsequently was austenitised at $800^{\circ} \mathrm{C}$ for $1 \mathrm{~h}$ and austempered at $260^{\circ} \mathrm{C}$ for $2 \mathrm{~h}$. The matrix microstructure exhibits fine lower bainite sheathes and inter-lath austenite (see Figure 1). The white eutectic carbide structures present in the as-cast microstructure remained after heat treating, indicating the austenitisation process was incomplete. There is also evidence of constituent segregation. Graphite nodules were also visible in the microstructure. 


\section{B. Hardness Testing and Fatigue Crack Testing}

Variation in hardness along the length and breadth of specimens was investigated by the generation of a hardness map, using a grid of hardness indents. A Vickers Pyramid Hardness Testing Machine was used with a load of $20 \mathrm{~kg}$. Local microhardness readings were also taken using a Micro Hardness Tester (HHT-1). A load of 300g was used for a dwell time of 10 seconds.

A three-point bend set up (Figure 2) was used for short crack tests which were performed on $12 \times 12 \times 80 \mathrm{~mm}$ cross-section standard bend-bar specimens, in air, at room temperature on a digitally controlled Instron 8501 servo-hydraulic at $5 \mathrm{~Hz}$. A peak opening stress was produced above the centre roller in three-point bend, decreasing to zero above the outer rollers. The maximum applied top surface stresses were $300,400,500,600,700$ and $800 \mathrm{MPa}$, at $\mathrm{R}=0.1$. The top surface of each bend bar was ground and polished before testing. Etching (using 2\% Nital) of the top surface was used to reveal the matrix microstructure on some of the specimens. Complete replica records of the specimen top surface were taken at suitable intervals (between 200-1000 cycles) under mean load. This was achieved by softening blocks of acetate in acetone and pressing them onto the top surface of the bend bar. These were then left to harden for about five minutes and were removed for subsequent analysis. From study of the replica record, the number of cracks, their positions and relative lengths, as a function of the number of cycles were determined. Measurements of projected crack lengths normal to the tensile axis from the digital images of the acetate replica record were performed using KS 300 on a PC running WinNT. The calculation of $\Delta \mathrm{K}$ was performed using equations as proposed by Scott 
and Thorpe ${ }^{[8]}$ based on assumptions made for a semi-elliptical short crack. Values of the specimen surface crack tip intensity factor $(K)$ are given by the following equation:

$$
K_{I}=\left\lfloor\left[M_{f 0}\left(1-0.3 \frac{a}{W}\right)\left(1-\left(\frac{a}{W}\right)^{12}\right)\right]+\left[0.394 E(k)\left(\frac{a}{W}\right)^{12} \sqrt{\frac{a}{c}}\right]\right\rfloor \frac{\sigma}{E(k)} \sqrt{\pi a}
$$

Where the surface correction factor is:

$$
M_{f 0}=\left[1.21-0.1\left(\frac{a}{c}\right)+0.1\left(\frac{a}{c}\right)^{4}\right] \sqrt{\frac{a}{c}}
$$

and the elliptical integral is:

$$
E(k)=\left[1+1.47\left(\frac{a}{c}\right)^{1.64}\right]^{0.5}
$$

following Scott and Thorpe's notation: $a$ is the crack depth, $c$ is half the surface crack length and $W$ is the specimen height (as shown in Figure 2). In order to investigate the effect of specimen microstructure on crack propagation under well defined stress states, a number of three-point bending long fatigue crack tests were performed on single-edge notched-bend (SENB) bars with a pre-existing slot of an $\mathrm{a} / \mathrm{W}=0.25$. The notch was sharpened with a razor blade to promote crack initiation. Long crack growth behaviour was established by load shedding down to threshold (da/dN $\sim 10^{-8}$ $\mathrm{mm} /$ cycle) in $10 \%$ steps in $\Delta \mathrm{K}$, each load shedding step was preceded by growth through 4 monotonic plastic zone sizes at constant $\Delta \mathrm{K}$ levels. Thresholding was followed by growth of the crack under constant load and increasing $\Delta \mathrm{K}$ conditions until fast fracture occurred. The final $\mathrm{K}_{\max }$ value achieved prior to final failure was taken to be an approximation to the cyclic $\mathrm{K}_{\mathrm{Q}}$ value of the material. Crack length was monitored by conventional D.C.P.D. techniques. 


\section{Microstructural Features Analysed by FBT and SUPANOVA Techniques}

To assess both the carbide distribution and degree of variability, ten to twelve overlapping images of the specimen top surface were assessed by using standard image analysis techniques. The acquisition software used was X-cap for WinNT by Epic. In addition, Finite Body Tessellation (FBT) and SUpport vector Parsimonious ANalysis Of VAriance (SUPANOVA) techniques have been applied to this material to describe the carbide distribution features ${ }^{[9,10,11]}$.

\section{FBT approach $^{[9,10]}$}

The identification of a tessellated cell around each individual secondary phase body, such that every point within the cell is closer to that body than any other, can be a powerful analysis tool, allowing detailed characterisation of local particle/secondary phase environments. To carry out a quantitative assessment of the local microstructure of a crack initiation site, a 'finite body' tessellation has been employed. In this, the tessellated cells are constructed from the interfaces of the finite-sized bodies resulting in a network of cells such that any point within a cell is closer to the body of the corresponding object, independent of particle size and shape distributions. The carbides in the ADI have a wide range of sizes and aspect ratios; hence this approach is particularly suitable. Eleven measurements can be derived from each cell as shown in Figure 3: $x_{1}$, area of the object, OA, (in this case the crack initiating features); $x_{2}$, object aspect ratio, OAr, which is a ratio of the minimum and maximum object dimensions; $x_{3}$, orientation of the object, OAng, the maximum with respect to the horizontal axis (in this case the tensile axis); $x_{4}$, area of the cell, CA, surrounding the object; $x_{5}$, cell aspect ratio, CAr; $x_{6}$, cell angle, CAng, angle of the cell's longest chord 
with respect to the horizontal; $x_{7}$, local area fraction (LAF), $A_{\mathrm{f}}$, which is a ratio of the object area to that of it's associated cell $(\mathrm{OA} / \mathrm{CA}) ; x_{8}$, number of near neighbours, $\mathrm{NN}$, for a binary object which is defined in terms of cells sharing boundaries with this object; $x_{9}$, nearest neighbour distance, $d_{\min }$, is the distance (edge to edge) from a binary object to its nearest neighbour; $x_{10}$, mean near neighbour distance, $d_{\text {mean }}$ is the average of the near neighbour distances; $x_{11}$, nearest neighbour angle, NNA, is the orientation angle with respect to the horizontal of a straight line which links the centre of mass of the binary object to that of its nearest neighbour

\section{SUPANOVA approach}

In addition to simply examining significant differences (or classifying features) in terms of individual FBT parameters, the SUPANOVA adaptive numerical modelling technique was also applied to identifying statistically significant differences between different populations of particles in terms of more complex combinations of the FBT features (i.e. a classification problem). Many classification techniques place an emphasis on obtaining a good classification rate (e.g. 100\% successful classification of those particles which crack on loading), but it is also important to be able to interpret the classification model in relatively simple terms, whilst still retaining good predictive capability. Such interpretations enable assessment of the physical mechanisms operating and hence allow physically based optimisation of the process in question. The ability to understand the underlying model input/output relationship is often overlooked in the case of classification. The SUPANOVA technique ${ }^{[12,13]}$ has been extended from regression to the domain of classification enabling a predictive model with a high degree of interpretability to be recovered. A more detailed description of the approach taken to incorporate the misclassification cost and performance criteria for imbalanced data can be found in Ref. ${ }^{[14]}$. The formulation 
embodies the principle of structural risk minimisation developed by Vapnik ${ }^{[15]}$ and uses kernels to calculate the non-linear transformation. Support vector machines produce essentially 'black box' predictive models, i.e. they can produce very accurate models, but the relationship between inputs and outputs is difficult to visualise. Transparency can be introduced by the use of the SUPANOVA framework, where an Analysis of Variance (ANOVA) functional decomposition of the form:

$$
f(x)=f_{0}+\sum_{i=1}^{d} f_{i}\left(x_{i}\right)+\sum_{i=1}^{d} \sum_{j=i+1}^{d} f_{i, j}\left(x_{i}, x_{j}\right)+\ldots .+f_{1,2 \ldots, d}(x)
$$

is used within the kernel. Where $\boldsymbol{x} \in \mathbf{R}^{d}, d$ is the number of inputs and $f_{\mathrm{o}}$ is the bias and the rest of the terms are univariate, bivariate, etc. components. The fact that each of the terms is additive makes it possible to interpret the sub-functions individually. In SUPANOVA a sparse representation of these terms is then chosen to give maximum transparency without sacrificing predictive accuracy as detailed in Ref. [12].

\section{RESULTS}

\section{A. Hardness Testing}

FBT analyses were carried out in the areas between the hardness indents, allowing a comparison of local microstructure variation with local hardness values (which was taken as the average of the 4 hardness values at the corners of each area). The eutectic carbide distribution analysis of the area covered by the hardness map revealed a variation in carbide area fraction, which could be linked to cooling variations experienced in the sand casting. It was clear that regions with proportionally greater carbide area fractions exhibited higher hardness. Micro-hardness tests indicated that the eutectic carbides have hardness values in excess of $750 \mathrm{H}_{\mathrm{V}}$. This indicates an increase in hardness of at least $60 \%$ when compared to the surrounding matrix (461 
$\mathrm{H}_{V}$ ). Based upon a microstructural evolution model developed by Thomson et al ${ }^{[16]}$ that has been linked to mechanical property predictions in these ADI systems, the overall estimated strength level of the ADI is $1170 \mathrm{MPa}$.

\section{B. Short Fatigue Crack Testing}

Twenty three short fatigue crack tests have been conducted within the $300-800 \mathrm{MPa}$ maximum applied stress testing range (well below the estimated yield stress of this material). Observations of the short fatigue crack test replica records have indicated a wide range of damage processes. The extent, number and density of coalescence events appeared critical in determining the fatigue lifetime of a specimen at any applied stress level. When the number or density of individual micro-cracks was low, the failure mechanism was dominated by crack propagation with a minimal influence of coalescence events. Conversely, when the number or density of micro-cracks was high, the growth of the dominant crack was strongly influenced by coalescence events and interactions with neighbouring cracks. Many specimens showed extensive crack interaction and coalescence events. Short crack growth rate data was gathered for those cracks that grew without significant coalescence events for comparison with conventional long crack data.

The eutectic carbides remaining from the as-cast material proved to be responsible for the initiation of the majority of micro-cracks, except in some rare circumstances where porosity was responsible for crack initiation. The eutectic carbides, being very brittle, cracked easily (Figure 4). The cracking was not always perpendicular to the applied tensile axis and the subsequent nucleation of micro-cracks into the matrix was rapid. For the fatigue crack tests performed above a maximum applied stress of 500 
$\mathrm{MPa}$, the first initiation events were seen on application of mean load $(>275 \mathrm{MPa})$ prior to cyclic loading. The number of eutectic carbides that cracked on initial loading is variable, ranging from 1 to 400, and appears to control the regime of fatigue failure. Further initiation occurred throughout the lifetime of a specimen. Initiation sites were always eutectic carbides.

A large degree of scatter is apparent in the lifetime data for the short fatigue crack specimens (see Figure 5). Furthermore, overlapping performance between applied stress levels can be observed, such that some specimens exhibit longer lifetimes than those tested at a lower maximum stress (Figure 6). Preliminary investigations revealed an approximate relationship between carbide area fraction (measured directly from the test surface before failure), applied stress level and lifetime. It can be observed that at all stress levels a high area fraction of eutectic carbide is deleterious to the lifetime of a specimen (Figure 7), and that this relationship is at its most apparent for specimens tested at $600 \mathrm{MPa}$. No fatigue failure occurred when specimens were tested at a maximum stress level of $300 \mathrm{MPa}$ (run-out was defined to have occurred when no failure was observed after more than a million cycles).

\section{Long Fatigue Crack Testing}

Long fatigue crack testing has identified values of $\Delta \mathrm{K}_{\text {th }}$ (threshold) and $\mathrm{K}_{\mathrm{Q}}$ (nominal cyclic toughness). The value for fatigue threshold $(5.8 \mathrm{MPa} \sqrt{\mathrm{m}})$ for the current heat treatment is comparable to that of the as-cast ductile iron $(6.0 \mathrm{MPa} \sqrt{\mathrm{m}})^{[17]}$ whilst values of $\mathrm{K}_{\mathrm{Q}}$ seem highly variable (from 18 to $27 \mathrm{MPa} \sqrt{\mathrm{m}}$ ). Comparison of the carbide area fraction of the side crack region for each of the long crack specimens 
suggests that this may be a feature in determining toughness. It was noted that specimens with higher carbide area fractions exhibited lower values of $\mathrm{K}_{\mathrm{Q}}$. Fatigue threshold and constant load amplitude growth out tests allow the observation and comparison of fracture surfaces corresponding to varying values of $\Delta K$. Figure $8(a)$ represents the fracture surface at fatigue threshold. The conspicuous flat regions in the micrographs are brittle facets representing cracked eutectic carbides. It is apparent that as the value of $\Delta \mathrm{K}$ experienced by the crack increases, the number of brittle facets on the fracture surface appears to increase (Figure 8(b)). Additionally, at high values of $\Delta \mathrm{K}$ ductile tearing was also visible in regions between brittle facets. This can be related to a probable increase in static monotonic failure modes as $\mathrm{K}_{\max }$ approaches $\mathrm{K}_{\mathrm{Q}}$.

The comparison of long and short fatigue behaviour in Figure 9 reveals classic fatigue behaviour. The short crack data was obtained from a sample tested at a maximum stress of $600 \mathrm{MPa}$ with a low carbide area fraction and exhibits a far greater degree of scatter than the long crack data. At comparable levels of $\Delta \mathrm{K}$ the short crack data shows increased crack growth rates. At higher values of $\Delta K$, the short crack data shows less scatter and approaches the long crack regime. However, unlike typical observations in other systems ${ }^{[18]}$, the short crack growth rate data does not merge completely with the long crack growth rate data at higher values of $\Delta \mathrm{K}$.

\section{ANALYSIS OF MICROSTRUCTURAL FEATURES}

\section{A. Crack Initiation Induced by Eutectic Carbides}


Figure 10 shows the extent of carbide cracking on initial loading to mean stress in the fatigue crack specimens and is correlated to final fatigue life. The crack number density was determined from replica records by counting the number of cracks in regions where the stress varied by only $50 \mathrm{MPa}$ either side of the axis of peak applied stress. Tests performed at a maximum stress of $500 \mathrm{MPa}$ or less failed to crack carbides on initial loading to mean stress (275MPa). Cracked carbides were however observed on the replicas taken at the first interval (approximately 10000 fatigue cycles) for all of the $500 \mathrm{MPa}$ tests. It can be seen there is significant variability between specimens particularly for specimens tested with a maximum stress of 700 $\mathrm{MPa}$. Furthermore, it appears in general, that the number of cracked carbides on initial loading has a significant effect in determining the lifetime of a fatigue crack specimen; the higher the number of cracks on initial loading, the shorter the fatigue lifetime.

\section{B. FBT Analysis}

Individual crack initiating eutectic carbides were assessed and compared to the background population using the finite body tessellation (FBT) approach. The analysis was performed after specimen fracture. Therefore measurement of which eutectic carbides cracked along the dominant crack that caused failure was not possible although separation of which carbides cracked on initial loading and which cracked later in the fatigue lifetime was determined from comparison with the replica record.

Simple comparisons between cracked carbides and the background population in terms of means and standard deviations of the FBT parameters are summarised in 
Table I. It is apparent that there is significant difference in means between the two classes when regarding carbide area, cell area, local area fraction, number of near neighbours, and mean near neighbour distance although significant scatter is observed. Therefore, as a first approximation, large carbides that tend towards a long and thin profile with a high local area fraction show a greater probability of fracture. The remaining tessellation parameters show little apparent difference between the cracked and non-cracked classes.

The tessellation parameters showing the most significant variation have been plotted as histograms in Figure 11 to compare population differences in more detail. In general, carbides that cracked are larger than the background population (Figure 11(a)). There is a little obvious variation in carbide aspect ratio populations (Figure 11(b)), whilst Figure 11(c) suggests that cracked carbides tend to exhibit larger cell areas. Figure 11(d) shows cracked carbides tending towards larger local area fractions. Furthermore, Figure 11(e) shows the cracked carbide population distribution is skewed to a larger number of near neighbours than the background population. This suggests that clustering of carbides is deleterious to the initiation resistance of the material. Figure 11(f) however, counters this statement by suggesting that cracked carbides have, perhaps in general, slightly larger mean near neighbour distances. It is obvious that cracked carbides show differences from the general population. Furthermore, it is probable that the factors contributing to the failure of these carbides are a complex function of multiple parameters. An adaptive numerical modelling approach has therefore been used to further investigate the classification differences between the cracked and non-cracked carbide populations. 


\section{SUPANOVA Approach Analysis}

An adaptive numerical modelling SUPANOVA approach ${ }^{[12,13]}$ was used to further interpret the large amount of FBT generated data and to assess all possible combinations of these tessellation parameters. This predictive model retains a high degree of interpretability and should provide a mechanistic insight to allow physically based optimisation of the process.

In order to quantify the process of crack initiation in the fatigue crack specimens a comparison was made between cracked carbides and the background population in the specimen exhibiting the greatest amount of crack initiation. Tessellation data for 1236 carbides was gathered. This data was divided into two classes; 78 cracked carbides and the background population (1158 carbides). In order to prevent a bias operating for the heavily represented (background population) class differing misclassification costs and a Geometric mean $\left(\mathrm{G}_{\text {mean }}\right)$ were used. A Geometric mean favours a balanced classification by measuring the square root of the product of the class classification $\operatorname{rates}^{[19]}$.

The normalisation of the eleven tessellation parameters between 0 and 1 avoided bias for any particular feature. The data was partitioned into training and testing sets. $45 \%$ of the data was used for training, with the remainder used for testing. A good classification performance was obtained by tuning the misclassification costs (based on $G_{\text {mean }}$ of the unseen data) using the pure support vector machine approach. This partitioning of data was performed ten times with a random selection of the training and testing data on each occasion. This provided ten models. 
The model was run using nine of the eleven tessellation parameters since it was decided that cell aspect ratio and cell angle did little to describe the distribution of a carbide population. The full ANOVA decomposition of the nine tessellation parameters has $512\left(2^{9}\right)$ possible terms. It was possible however, to reduce this number of terms without greatly compromising overall performance by using the sparse representation approach of the ANOVA decomposition within the SUPANOVA process. The 512 possible terms were reduced to just five. The sparse representation model gave a successful cracked carbide classification rate of $78 \%$, a successful 'non-crack' classification of $86 \%$ and an overall classification performance based on the mean and variance values of $G_{\text {mean }}$ for each of the ten data set runs of $82 \%$ and $0.009 \%$ respectively. A low variance indicates similar values of $G_{\text {mean }}$ for each of the ten models.

Figure 12 represents the relationships suggested by the SUPANOVA model and are shown with the corresponding data spread for the term(s) selected. As shown in Figure 12(a), the first term selected by the SUPANOVA model is the univariate relating increasing cell area with the increasing probability of an individual carbide cracking. The second univariate relationship to be picked out by the classifier was the increasing probability of crack initiation with an increase in local area fraction and is shown in Figure 12(b). These two relationships were picked out by all of the ten dataset sampling runs. The only other univariate selected was the decreasing likelihood of crack initiation with increasing nearest neighbour distance (Figure 12(c)). This term was selected by nine out of the ten data-set sampling runs. 
The following bivariates were selected by the classifier; carbide angle vs. local area fraction (Figure 13(a)); and carbide angle vs. nearest neighbour angle (Figure 13(b)). Only the first of the above bivariate terms was selected by all of the data-set sampling runs. The relationship described by this term sees an increase in the probability of crack initiation with an increase in carbide angle and local area fraction. The second bivariate (selected on six out of ten occasions) describes a decrease in crack initiating probability with an increase in carbide angle and nearest neighbour angle. In both cases the distribution of cracked and background carbides is also shown next to the relevant SUPANOVA plots.

\section{DISCUSSION}

\section{A. Microstructure and Hardness}

In the ADI microstructure, graphite nodules are comparatively very soft with respect to the matrix. The matrix itself is formed by two main constituents (retained austenite and bainite), the hardness values of which are quite different. The growth of bainite sheaves away from the graphite nodules, leaves regions of supersaturated austenite in areas remote from nodules. Therefore, as the distance from the graphite nodules increases, the proportion of austenite increases. Since retained austenite is a softer phase than bainite the hardness value is expected to decrease in these areas. The presence of constituent segregation and eutectic carbides in the austenitised microstructure may further increase the complexity of this hardness gradient. The distribution and proportion of these constituents therefore has a great significance on hardness. This local microstructural variation in hardness is a significant factor when 
considering crack initiation in or propagation through such a region. The hardness value mapping of the bend bar specimen revealed a variation in hardness which correlated with a similar gradient in the local eutectic carbide area fraction of the same specimen. The higher the eutectic carbide area fraction is, the greater the local hardness value. This is not unexpected since the hardness of individual carbides $(\sim 750$ $\left.\mathrm{H}_{\mathrm{v} 20}\right)$ is $60 \%$ greater than that of the surrounding matrix.

\section{B. Fatigue Crack Failure Mechanisms}

The number of primary initiation sites has a profound impact on the mechanism of failure and ultimately the lifetime of the specimens. Whilst porosity existed in the microstructures, the primary crack initiators were eutectic carbides. Replicas taken on application of mean load greater than $275 \mathrm{MPa}$ before fatigue cycling revealed the presence of crack initiation sites. This indicates an easy initiation stage, with the hard, brittle carbides cracking easily on application of loads of $275 \mathrm{MPa}$. Additionally, micro-crack initiation events were observed throughout the lifetime and appeared dependent on microstructure and stress range.

A large variability in the number of carbides cracking on initial loading to a mean stress of $385 \mathrm{MPa}$ and $330 \mathrm{MPa}\left(\sigma_{\max }=700 \mathrm{MPa}\right.$ and $600 \mathrm{MPa}$ respectively) was observed. For the most damaged specimen over 400 eutectic carbides cracked on initial loading to mean stress. This is compared to figures of less than ten for the least damaged specimens. No cracked carbides were observed on loading to a mean stress of less than or equal to $275 \mathrm{MPa}$. It is therefore reasonable to assume an applied stress between $275 \mathrm{MPa}$ and $330 \mathrm{MPa}$ is required to cause eutectic carbide fracture in this microstructure. Indeed, the presence of cracked carbides on replicas taken at the first 
interval for all tests with a mean stress of $275 \mathrm{MPa}$ or less indicate the increase to maximum stress during the first fatigue cycle is sufficient to cause carbide fracture.

It is likely the brittle eutectic carbides decrease the toughness of a microstructure by increasing the proportion of static failure modes. Evidence of an increase in the number of brittle facets (and hence static failure modes) visible on the fracture surface has been observed with a corresponding increase in values of $\Delta \mathrm{K}$. Furthermore, as values of $\Delta \mathrm{K}$ approach $\mathrm{K}_{\mathrm{Q}}$ regions of micro-void coalescence can be seen on the fracture surface. These areas are perhaps further evidence of an increase in static failure modes as the specimen approaches fracture and can be compared to similar fracture surface observations of short crack specimens suffering coalescence dominated failure. It is therefore reasonable to suggest that the faster crack growth rates can be related to increased numbers of static failure modes associated with the presence of eutectic carbides. In support of this, lower $\mathrm{K}_{\mathrm{Q}}$ values were observed for samples containing higher proportions of eutectic carbides.

\section{The Principle of Load Transfer}

The system of brittle carbides in a relatively ductile matrix found in this material can be compared to that of typical discontinuously reinforced Metal Matrix Composite (MMC). Common discontinuous MMCs are Al based alloys reinforced with $\mathrm{SiC}$ or $\mathrm{Al}_{2} \mathrm{O}_{3}$ particles. The size of the particles $\left(1-100 \mu \mathrm{m}^{2}\right)$ and the volume fraction $(5-$ $40 \%$ ) in discontinuous MMCs create a situation where there is a significant amount of load transfer to the reinforcement from the matrix ${ }^{[20]}$. The principle of load transfer is fundamental to the understanding of the mechanical properties of MMCs, which also can be applied to the current material as the load is shared by the matrix and the 
carbides when the specimen is subjected to applied stress. The proportion of the external load borne by each of these phases can be gauged by volume averaging the load within them such that at equilibrium:

$$
\sigma_{A}=(1-f) \bar{\sigma}_{m}+f \bar{\sigma}_{i}
$$

Where $\sigma_{A}$, represents the external stress, while $\bar{\sigma}_{m}$ and $\bar{\sigma}_{i}$ are the volume averaged stress of the matrix and inclusion respectively. The inclusion volume fraction is represented by $f$. Therefore a certain proportion of the load is carried by the inclusion (carbides) and the remainder by the matrix. Under elastic conditions this proportion will be independent of applied load and represent an important characteristic of the material.

The identification of a threshold value of stress, above which carbide cracking is seen to occur, allows the estimation of a minimum carbide fracture stress. Since inclusion stress is approximately independent of size ${ }^{[20]}$, fracture stresses have been evaluated for specific cracked carbides of varying aspect ratio and alignment. Finite Body Tessellation (FBT) data from the specimen containing the largest number of cracked carbides was used for this analysis. Fracture stresses for cracked carbides with the highest and lowest aspect ratios were evaluated using the Eshelby approach ${ }^{[21]}$. Additionally, carbides with the highest aspect ratio perpendicular (oblate) and parallel (prolate) to the tensile axis were considered. Carbides of low, mid and high values of aspect ratio were selected that deviated from the prolate and oblate orientations as little as possible. Values of $190 \mathrm{GPa}$ and $160 \mathrm{GPa}$ were taken for the Young's modulus and 0.27 and 0.3 for the Poisson's ratios of the eutectic carbides $\left(\mathrm{Fe}_{3} \mathrm{C}\right)$ and bulk ADI respectively ${ }^{[22,23,24]}$. Inclusion stresses were calculated for the upper and lower estimations of applied stress required for carbide fracture (330 MPa and 275 
$\mathrm{MPa})$ and are summarised in Table II. The lowest inclusion stresses ( $\sim 302 \mathrm{MPa})$ are shown by oblate particles with aspect ratios 1.73 to 2.37 . The highest inclusion stresses are shown by prolate particles with stress increasing with aspect ratio. However, it should be remembered that the orientations of the eutectic carbides are not exactly prolate or oblate. Additionally, since the average carbide geometry is far from ellipsoidal these figures can only be regarded as first approximations of carbide fracture stress.

Despite the fact that inclusion stress is approximately independent of size, it is widely accepted that fracture at a given stress level occurs only when the particle contains a critical flaw, which is more likely for large particles ${ }^{[20]}$. The probability of a given flaw distribution containing this critical flaw increases with inclusion stress (as the critical flaw size will decrease). It is reasonable to propose that the probability of carbides containing a critical flaw is increased for large carbides and carbides with geometry and orientation that induces higher inclusion stresses by more efficient load transfer.

\section{Interpretation of Crack Initiating Carbide Classification}

The relationships predicted by the classifier of the SUPANOVA model were interpreted with caution, with particular attention being paid to the data spread and effective weighting. The effective weighting represents the highest or lowest value of the probability axis ('y-axis' for univariates and 'z-axis' for bivariates) where there is a reasonable spread of data. This provides an indication of the relative importance of the relationships. 


\section{Univariate relationships}

Simple comparison of mean values between crack initiating carbides and the background population (Table I) suggest that the propensity of individual carbides to fracture is promoted by the following features:

- Large carbide area

- Large cell area

- Large local area fraction (LAF)

The application of the SUPANOVA model also identified cell area and LAF as significant factors governing fatigue crack initiation. There are visibly more cracked carbides with higher cell areas and local area fractions than the background population. Whilst the data is relatively sparse for highest and lowest values of cell area and LAF, there appears to be adequate data to allow for confidence in the model prediction for the rest of the data range. The effective weightings for cell area and LAF were -5.0 and -2.8 respectively. This suggests cell area is the dominant feature in carbide fracture. Carbide area has been plotted as a function of both cell area and LAF in Figure 14(a) and Figure 14(b) respectively. It is noticeable that in general cracked carbides with a large cell area or LAF tend themselves to also be large. A large cell area or LAF in the background carbide population however, does not have such a strong correlation with a large carbide area.

The SUPANOVA model identifies the decrease in the likelihood of crack initiation with increasing nearest neighbour distance (Figure 12(c)). This perhaps suggests the 
location of the nearest carbide is influential in determining the susceptibility of individual carbides to cracking and acting as fatigue initiation sites. The data spread for this term is weighted to relatively low values of nearest neighbour distance and with an effective weighting of 1.5 is perhaps the least influential of the univariate relationships. However, the suggested relationship appears to a reasonable one within the range where there is a significant amount of data.

\section{Bivariate relationships}

With SUPANOVA we are also able to identify higher order interactions that are not easily identified by simple comparison of mean values. The first bivariate (see Figure 13(a)) suggests the likelihood of fracture is increased with increasingly locally clustered particles orientated at a high angle to the tensile axis. It is significant that this relationship was selected by all of the data set runs and had the strongest effective weighting at -1.7 suggesting it is a significant factor in determining the likelihood of carbide fracture. The other bivariate suggests that the likelihood of crack initiation is decreased if the nearest neighbour of oblate carbides is situated perpendicularly to the carbide with respect to the tensile axis (see Figure 13(b)). This was selected by $60 \%$ of the data set runs and with an effective weighting of 1.12 appeared to have a lesser influence. To summarise, large or long and thin carbides on the whole appear to be susceptible to fracture. Carbides that are locally clustered and aligned at a high angle to the tensile axis are particularly susceptible to fracture except when the nearest neighbour is situated perpendicularly to that carbide with respect to the tensile axis. This perhaps suggests the presence of possible stress shielding effects in local populations showing a high degree of alignment. 


\section{E. Crack Interaction and Coalescence Effects}

Crack interaction and subsequent coalescence is to varying extent a feature of all the short fatigue crack failure mechanisms of this study. In general, the types of coalescence events observed in the current study are as follows:

- The rapid formation of a dominant macro-crack by the early-life coalescence of two or more micro-cracks that initiated in close proximity. Micro-crack dimensions at coalescence are typically less than $100 \mu \mathrm{m}$.

- The coalescence of numerous micro-cracks throughout the lifetime of the specimens.

- Mid-life coalescence of relatively large micro-cracks. Both micro-cracks are typically of comparable length $(250 \mu \mathrm{m}$ to $500 \mu \mathrm{m})$ at coalescence.

- The coalescence of two large parallel offset non-coplanar dominant cracks of at least $1000 \mu \mathrm{m}$ on failure.

Kamaya et al. ${ }^{[25]}$ proposed the influence of the interaction between multiple cracks on crack growth behaviour greatly depends on the relative position of the cracks. Interaction is influenced not only by the relative position but also by the relative lengths of cracks. The influence is strongest when the crack lengths are equal and decreases as the difference in crack length increases. If the difference in crack length is greater than a certain level the interaction is sufficiently small to allow the influence of interaction to be ignored. The critical ratio in crack lengths was shown to be related to the magnitude of offset between the two cracks. The greater the offset is, the greater the requirement for similitude in crack length for there to be interaction. 
Coalescence in the specimens was typically of cracks of more comparable length and crack interaction is therefore likely to be more significant. However, this approach considers only pairs of cracks. Greno et al. ${ }^{[26]}$ and J Ortiz et al. ${ }^{[27]}$ proposed crack initiation ahead of the crack tip and subsequent crack interaction and coalescence is significant and responsible for low propagation rates and high threshold values for ADI alloys when compared to steels. These phenomena were attributed to the redistribution and reduction of the average near-tip stresses by micro-cracks ahead of the advancing dominant macro-crack. Parallel collinear non-coplanar semi-elliptical cracks are very sensitive to crack-tip shielding ${ }^{[28]}$. Larger cracks shield the tips of smaller cracks(s) from the applied stress or stresses until the latter become nonpropagating. The fatigue crack growth of larger cracks does not appear to be significantly affected by the presence of smaller cracks.

The multiplicity of initiation events and diversity of separation distances and relative positions does not allow for tractable models describing coalescence behaviour on a crack-by-crack basis. Multiple fatigue crack initiation and growth has been observed in different steels ${ }^{[29,30,31]}$. As the initial surface cracks propagate adjacent cracks coalesce into fewer cracks of lower aspect ratio. Once a dominant surface crack has formed by coalescence of numerous coplanar micro-cracks, growth occurs predominantly in the depth direction. J. Stolarz ${ }^{[32]}$ proposed the increase in surface crack length due to coalescence has no effect on crack growth rate until the crack reaches its equilibrium aspect ratio which occurs exclusively in the depth direction. It was also suggested for low cycle fatigue, crack coalescence of this nature at the surface has no significant influence on the kinetics of fatal crack growth. It therefore seems reasonable to suggest the critical factors for coalescence dominated fatigue 
crack failure is the extent of damage (number of cracked carbides) on loading to maximum stress and crack growth in the depth direction following coalescence, not the nature of coalescence on the surface.

\section{CONCLUSIONS}

1. The microstructure of the austempered ductile iron is typified by a fine lower bainitic matrix with variable quantities and distributions of eutectic carbides. The variable distribution of the carbide structures throughout the microstructure produced a range of fatigue failure behaviour from coalescence to propagation dominated failure.

2. Carbide cracking occurred when short fatigue crack specimens were subjected to a stresses between 275 - $330 \mathrm{MPa}$ (well below the estimated yield stress of the ADI material itself). In general, high carbide area fractions promote coalescence dominated fatigue crack failure whilst low area fractions promote propagation dominated fatigue crack failure.

3. The effect of carbide geometry and distribution has been investigated by classification of the features that cause individual carbides to crack and subsequently initiate micro-cracks. Large or long and thin carbides on the whole appear to be susceptible to fracture. Carbides that are locally clustered and aligned at a high angle to the tensile axis are particularly susceptible to fracture.

4. The nature of load transfer in carbide populations controls the internal stresses experienced by individual carbides. Load transfer mechanisms are influenced by the 
geometry and alignment of both the individual carbide and the overall population in addition to the carbide volume fraction.

\section{ACKNOWLEGEMENTS}

Materials and financial support from Federal-Mogul Camshafts and EPSRC Grant No GR/M13879 are gratefully acknowledged. 


\section{REFERENCES}

1. J. F. Janowak and R. B. Gundlach: Journal of Heat Treating, 1985, vol. 4, pp. 2531.

2. C. K. Lin and T. P. Hung: International Journal of Fatigue, 1996, vol. 18, pp. $297-$ 307.

3. C. K. Lin and T. P. Hung: International Journal of Fatigue, 1996, vol. 18, pp. 309-20.

4. D. A. Hill and D. Nowell: in Fretting Fatigue ESIS 18, Mechanical Engineering Publications, 1994

5. P. A. S. Reed, M. Joyce, N. Hide and J. Boselli: Report to Federal Mogul, University of Southampton, 1998.

6. R. P. Hockley, D. Thakar, J. Boselli, I. Sinclair and P. A. S. Reed: in Small Fatigue Cracks: Mechanics, Mechanisms and Applications, R. K. S. Ravichandran, R. Ritchie and Y. Murakami, eds. New York, Elsevier, 1999, pp. 49-56.

7. P. A. S. Reed, R. C. Thomson, S. James, D.C. Putman, K. K. Lee and S. R. Gunn: Materials Science and Engineering, 2003, vol. A346, pp. 273-86.

8. P. M. Scott and T. W. Thorpe: Fatigue of Engineering Materials and Structures, 1981, vol. 4, pp. 291-309.

9. J. Boselli, I. Sinclair, P.J. Gregson and P.D. Pitcher: Scripta Mater. 1997, vol. 38, pp. 839-44.

10. N. Yang, J. Boselli, P. J. Gregson and I. Sinclair: Materials Science and Technology, 2000, vol. 16, pp. 797-805. 
11. O. P. Femminella, M. J. Starink, S. R. Gunn, C. J. Harris and P. A. S. Reed: Materials Science Forum, 2000, vol. 331-337, pp. 1255-60.

12. S. Gunn and M. Brown: in Proc. IEEE International Workshop on Neural Networks for Signal Processing, Madison, Wisconsin, 1999.

13. M.C. Mwanza, M.R. Joyce, K.K. Lee, S.Syngellakis and P.A.S. Reed: International Journal of Fatigue, 2003, vol. 25, pp. 1135-45.

14. K.K. Lee, C.J. Harris, S.R. Gunn and P.A.S. Reed: in Proc. IPMM, 9 pages on CD ROM, 2001.

15. V. Vapnik: The Nature of Statistical Learning Theory, Springer-Verlag, Berlin, 1995.

16. R.C. Thomson, J.S. James and D.C. Putman: Materials Science and Engineering A, 2003, vol. 36, pp273-286

17. B. Stokes, PhD Thesis, University of Southampton, UK, 2003.

18 S. Suresh: Fatigue of Materials, Cambridge University Press, 1998

19. K.K. Lee, C.J. Harris, S. R. Gunn and P.A.S. Reed: in Proc: IJCNN, Washington DC, USA, 2001, pp. 2410-15.

20. T. W. Clyne and P. J. Withers: An Introduction to Metal Matrix Composites. 1995.

21. P. J. Withers, W. M. Stobbs and O. B. Pedersen, Acta Metallurgica, 1989, vol. 37, pp. 3061-84.

22. Cast Irons - ASM Specialty Handbook, The Materials Information Society, 1996

23. H. Mizubayashi, J. J. Li, H. Yumoto and M. Shimotomai: Scripta Materialia, 1999, vol. 40, pp. 773-77.

24. M, Umenoto, Z. G. Liu, K. Masuyama and K. Tsuchiya: Scripta Materialia, 2001, vol. 45, pp. 391-97. 
25. N. Kamaya and N. Totsuka: Corrosion Science, 2002, vol. 44. pp. 2333-52.

26. G. L. Greno, J. L. Otegui and R. E. Boeri: International Journal of Fatigue, 1999, vol. 21 , pp. $35-43$.

27. J. Ortiz, A. P. Cisilino and J. L. Otegui: Fatigue and Fracture of Engineering Materials and Structures, 2001, vol. 24, pp. 591-605.

28. W. O. Soboyejo and J. F. Knott: Fatigue and Fracture of Engineering Materials, 1991, vol. 14, pp. 37-49.

29. C. Bayley, G. Glinka and J. Porter: International Journal of Fatigue, 2000, vol. 22. pp. 799-808.

30. N. Gao, M. W. Brown and K. J. Miller: Fatigue and Fracture of Engineering Materials and Structures, 1995, vol. 18, pp. 1407-22.

31. N. Gao, M. W. Brown and K. J. Miller: Fatigue and Fracture of Engineering Materials and Structures, 1995, vol. 18, pp. 1423-41.

32. J. Stolarz: Materials Science and Engineering, 1977, vol. A234-236, pp. 861-64. 
Table I. Summary of individual cracks initiating carbide classification in short fatigue crack specimens.

\begin{tabular}{|c|c|c|c|c|}
\hline Property & Class & Mean & St dev & Coeff Var \\
\hline \multirow[t]{2}{*}{ Carbide Area $\left(\mu \mathrm{m}^{2}\right)(\mathrm{OA})$} & Cracked & 2533.7 & 2110.6 & 0.8 \\
\hline & Background & 471.2 & 955.0 & 2.0 \\
\hline \multirow[t]{2}{*}{ Carbide Aspect Ratio (OAr) } & Cracked & 2.2 & 1.1 & 0.5 \\
\hline & Background & 1.8 & 0.6 & 0.3 \\
\hline \multirow[t]{2}{*}{ Carbide Angle (radians) (OAng) } & Cracked & 0.9 & 0.4 & 0.5 \\
\hline & Background & 0.8 & 0.4 & 0.5 \\
\hline \multirow[t]{2}{*}{ Cell Area $\left(\mu \mathrm{m}^{2}\right)(\mathrm{CA})$} & Cracked & 15932.6 & 10455.0 & 0.7 \\
\hline & Background & 5797.5 & 5328.0 & 0.9 \\
\hline \multirow[t]{2}{*}{ Cell Aspect Ratio (CAr) } & Cracked & 1.6 & 0.4 & 0.2 \\
\hline & Background & 1.8 & 0.6 & 0.3 \\
\hline \multirow[t]{2}{*}{ Local Area Fraction $\left(\mathrm{LAF}=A_{\mathrm{f}}\right)$} & Cracked & 15.8 & 7.3 & 0.5 \\
\hline & Background & 8.2 & 7.8 & 0.9 \\
\hline \multirow[t]{2}{*}{ Number Near Neighbours (NN) } & Cracked & 8.1 & 3.0 & 0.4 \\
\hline & Background & 5.7 & 2.3 & 0.4 \\
\hline \multirow{2}{*}{$\begin{array}{l}\text { Nearest Neighbour Distance }(\mu \mathrm{m}) \\
\left(d_{\min }\right)\end{array}$} & Cracked & 7.1 & 8.4 & 1.2 \\
\hline & Background & 8.5 & 12.1 & 1.4 \\
\hline \multirow{2}{*}{$\begin{array}{l}\text { Mean Near Neighbour Distance } \\
(\mu \mathrm{m})\left(d_{\text {mean }}\right)\end{array}$} & Cracked & 56.7 & 27.8 & 0.5 \\
\hline & Background & 49.7 & 29.7 & 0.6 \\
\hline \multirow{2}{*}{$\begin{array}{l}\text { Nearest Neighbour Angle (rads) } \\
\text { (NNA) }\end{array}$} & Cracked & 0.8 & 0.5 & 0.6 \\
\hline & Background & 0.8 & 0.5 & 0.6 \\
\hline \multirow[t]{2}{*}{ No. Carbides (Class size) } & Cracked & \multicolumn{3}{|l|}{78} \\
\hline & Background & \multicolumn{3}{|l|}{1158} \\
\hline
\end{tabular}

Table II. Summary of inclusion stresses for selected cracked carbides.

\begin{tabular}{|c|c|c|c|c|c|c|c|c|}
\hline \multirow[t]{2}{*}{$\begin{array}{c}\text { Carbide } \\
\text { Aspect } \\
\text { Ratio }\end{array}$} & \multirow[t]{2}{*}{$\begin{array}{l}\text { Carbide } \\
\text { Area } \\
\left(\mu \mathrm{m}^{2}\right)\end{array}$} & \multicolumn{2}{|c|}{$\begin{array}{l}\text { Inclination with } \\
\text { Tensile Axis }\end{array}$} & \multirow[t]{2}{*}{$\begin{array}{l}\text { Assumed } \\
\text { Orientation }\end{array}$} & \multicolumn{2}{|c|}{$\begin{array}{c}\text { Deviation from } \\
\text { Actual } \\
\text { Orientation } \\
\end{array}$} & \multicolumn{2}{|c|}{$\begin{array}{c}\text { Inclusion } \\
\text { Stress - } \sigma_{I} \\
(\mathrm{MPa}) \\
\end{array}$} \\
\hline & & radians & degrees & & radians & degrees & $\begin{array}{l}\sigma^{\mathrm{A}}= \\
275 \\
\mathrm{MPa}\end{array}$ & $\begin{array}{c}\sigma^{\mathrm{A}}= \\
330 \\
\mathrm{MPa}\end{array}$ \\
\hline 1.04 & 2737 & 1.14 & 65.4 & Oblate & 0.43 & 24.6 & 304.8 & 365.7 \\
\hline 1.73 & 2701 & 1.46 & 83.7 & Oblate & 0.11 & 6.3 & 301.8 & 362.2 \\
\hline 2.05 & 5711 & 0.07 & 4.0 & Prolate & 0.07 & 4.0 & 314.3 & 377.2 \\
\hline 2.05 & 668 & 1.37 & 78.5 & Oblate & 0.20 & 11.5 & 301.7 & 362.0 \\
\hline 2.32 & 2369 & 0.04 & 2.3 & Prolate & 0.04 & 2.3 & 316.1 & 379.4 \\
\hline 3.9 & 1354 & 0.26 & 14.9 & Prolate & 0.26 & 14.9 & 323.0 & 387.6 \\
\hline 2.37 & 1178 & 1.47 & 84.3 & Oblate & 0.10 & 5.7 & 301.8 & 362.1 \\
\hline 3.52 & 6784 & 1.40 & 80.3 & Oblate & 0.17 & 9.7 & 303.6 & 363.8 \\
\hline
\end{tabular}




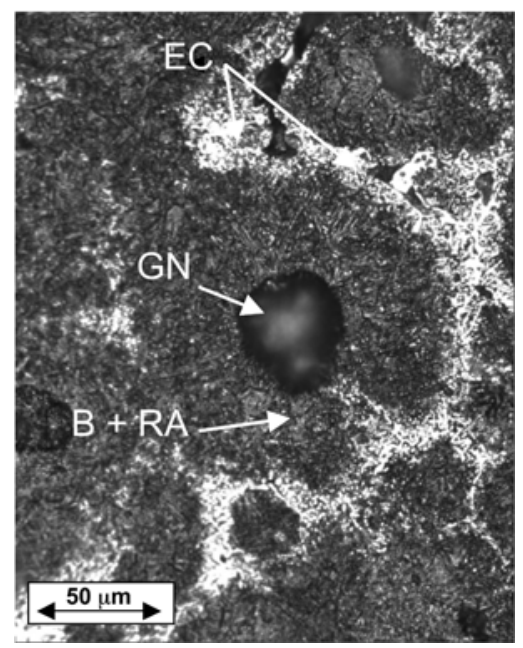

Fig. 1 ADI microstructure, etched in 2\% Nital. (EC - Eutectic Carbides; GN Graphite Nodules; B+RA - Bainite \& Retained Austenite).

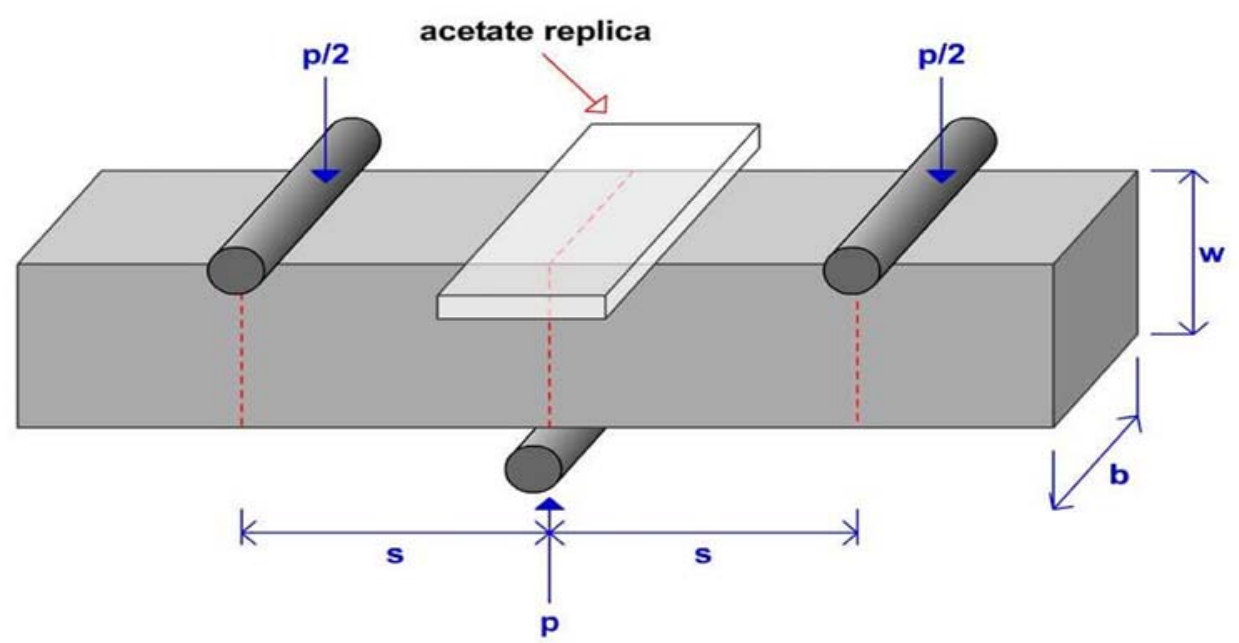

Fig. 2 Three-point bend short crack fatigue test set-up. $\mathrm{P}=$ applied load; $\mathrm{s}=$ separation. 

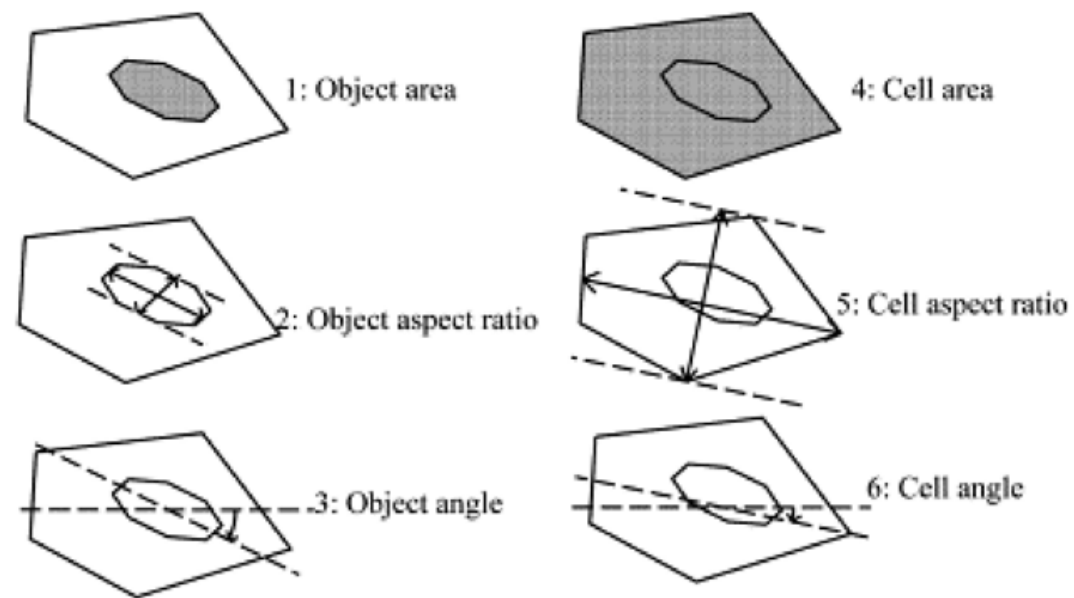

7: Local area fraction $=$ object area $(1) /$ cell $\operatorname{arca}(4)$

(a)

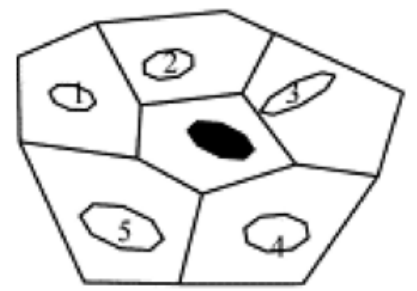

8: Number of near neighbours
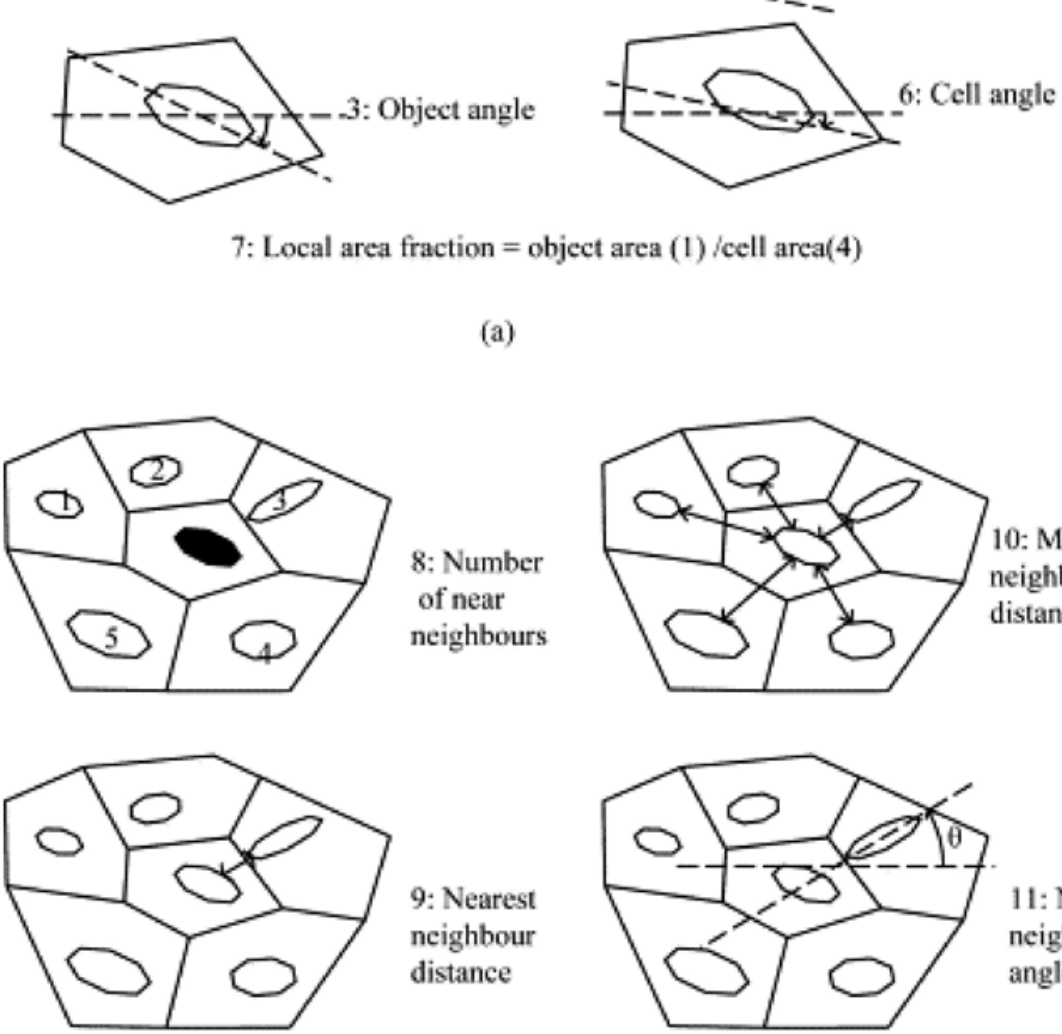

9: Nearest neighbour distance
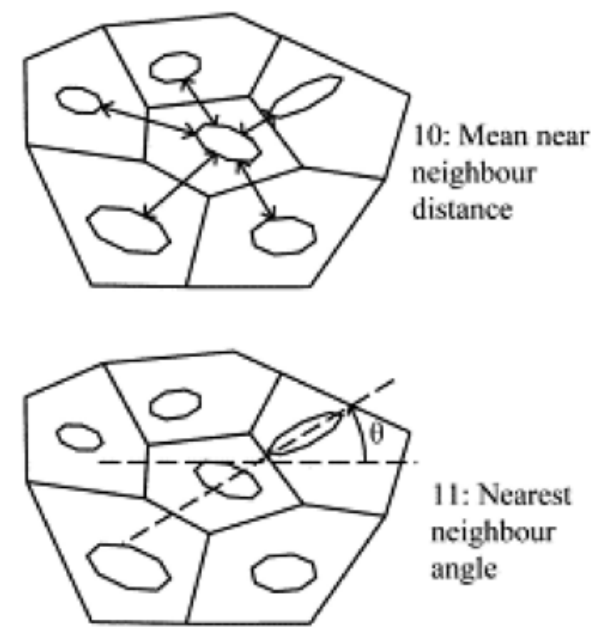

11: Nearest neighbour angle

(b)

Fig. 3 Definitions of tessellation measurements: (a) single cell measurements; (b) cell and near neighbour measures.

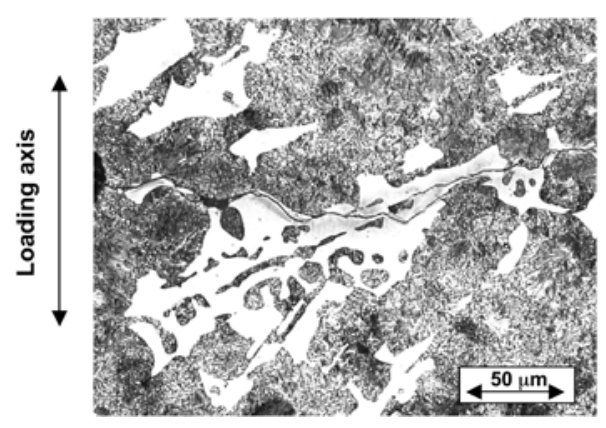

Fig. 4 Example of fatigue crack initiation in short fatigue crack specimen. 


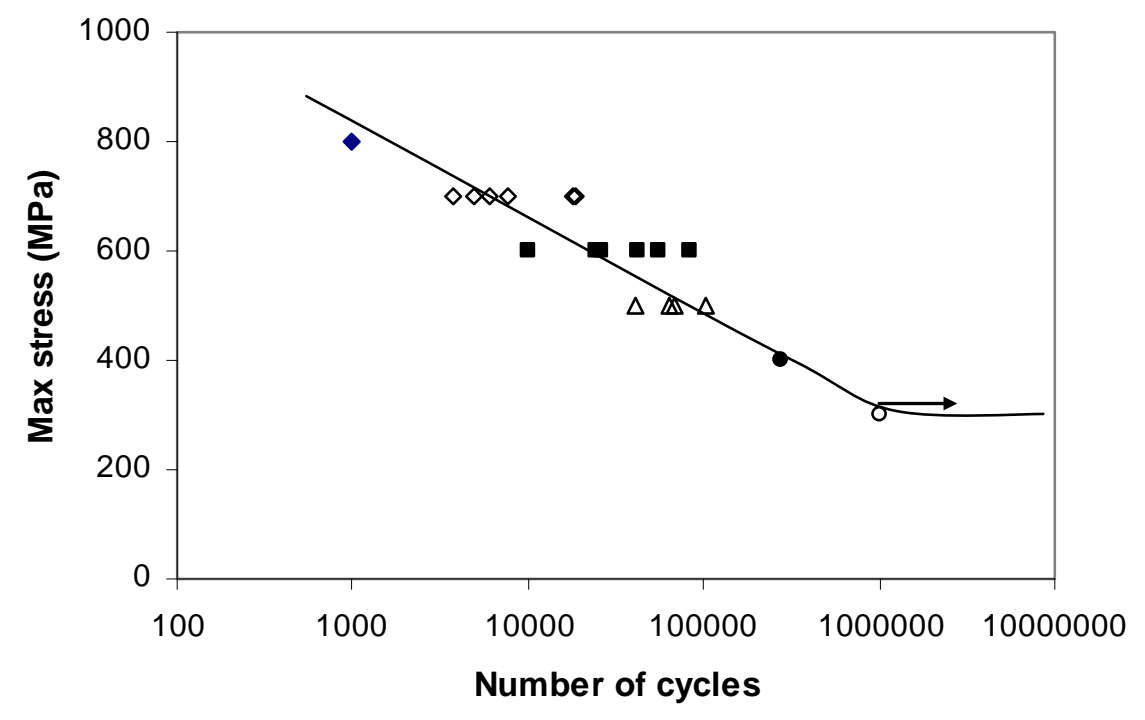

Fig. 5 S-N curve for all short fatigue crack specimens in terms of the maximum applied stress.

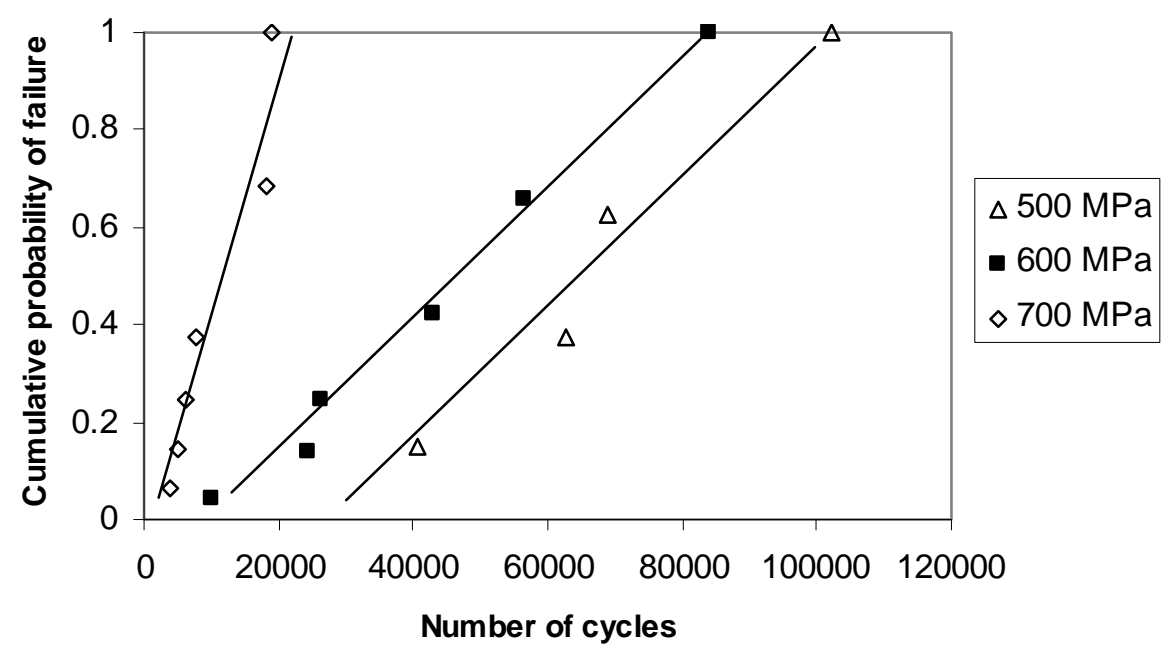

Fig. 6 Relationship between cumulative probability and fatigue life for short fatigue crack specimens. 


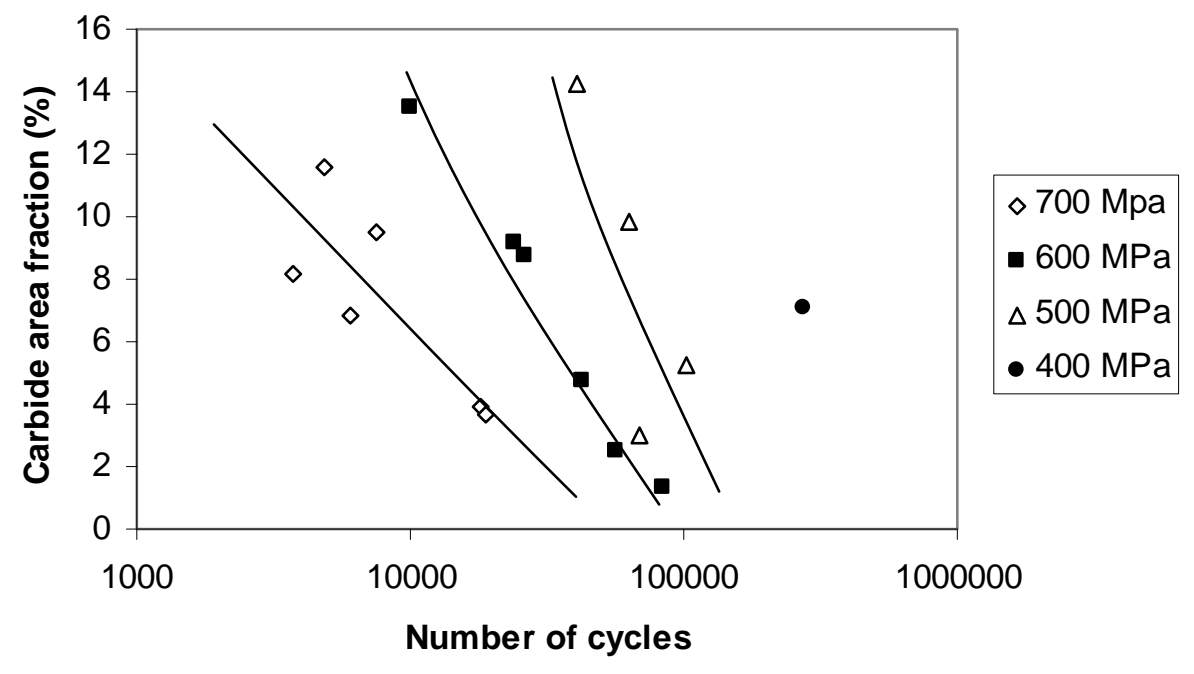

Fig. 7 Relationship between carbide area fraction and fatigue life for short fatigue crack specimens.
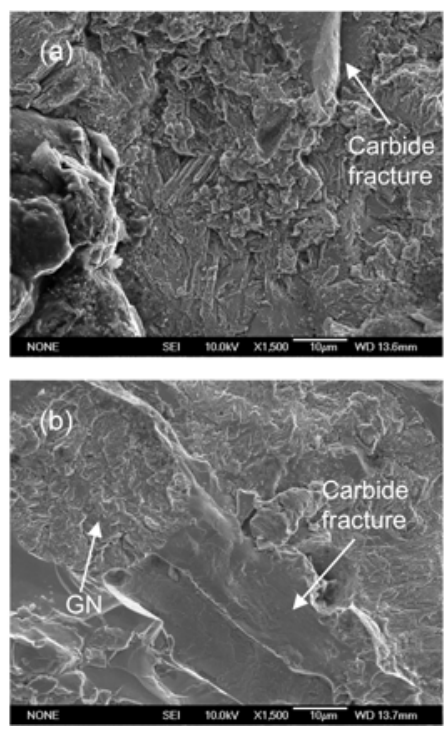

Fig. 8 Fatigue surface of threshold and growth out test specimens.

(a) $\Delta \mathrm{K} 5.8 \sim \mathrm{MPa} \sqrt{\mathrm{m}}$; (b) $\Delta \mathrm{K} 15 \sim \mathrm{MPa} \sqrt{\mathrm{m}}_{\mathrm{m}}$. 


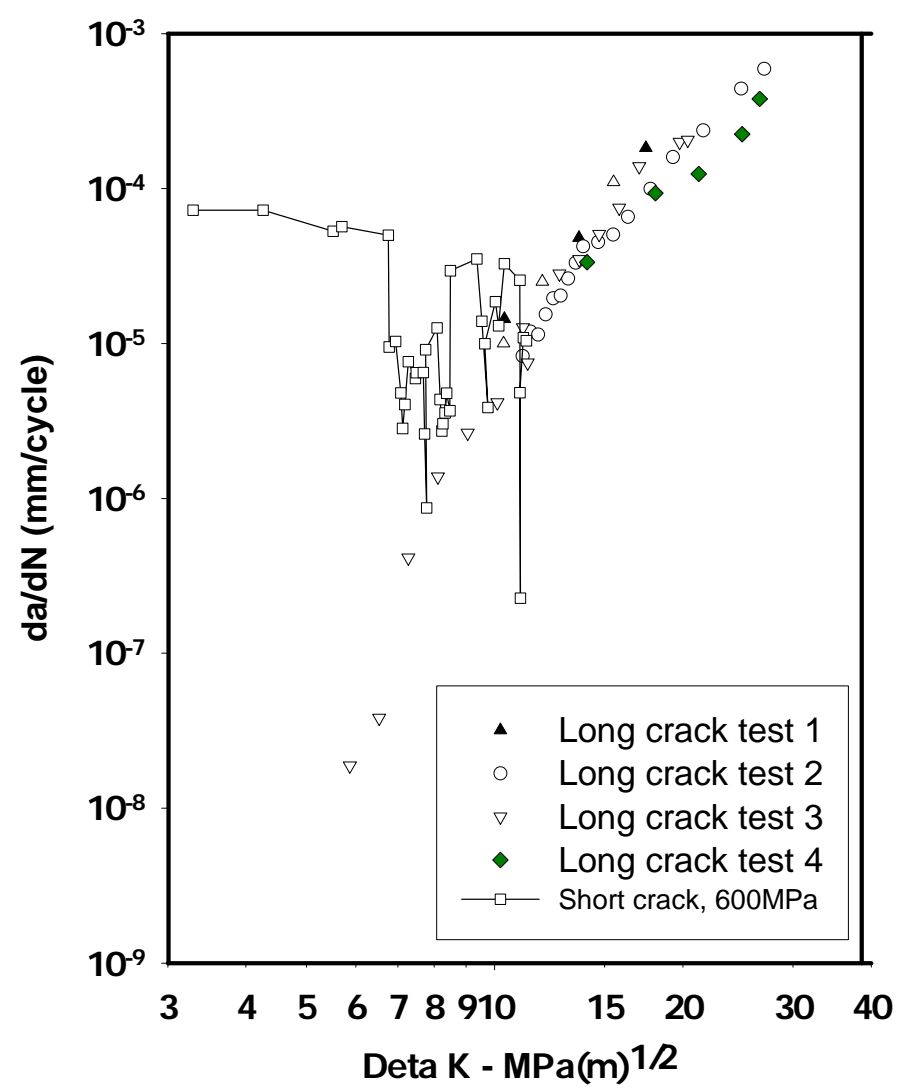

Fig. 9 Comparison of long and short fatigue crack data. 


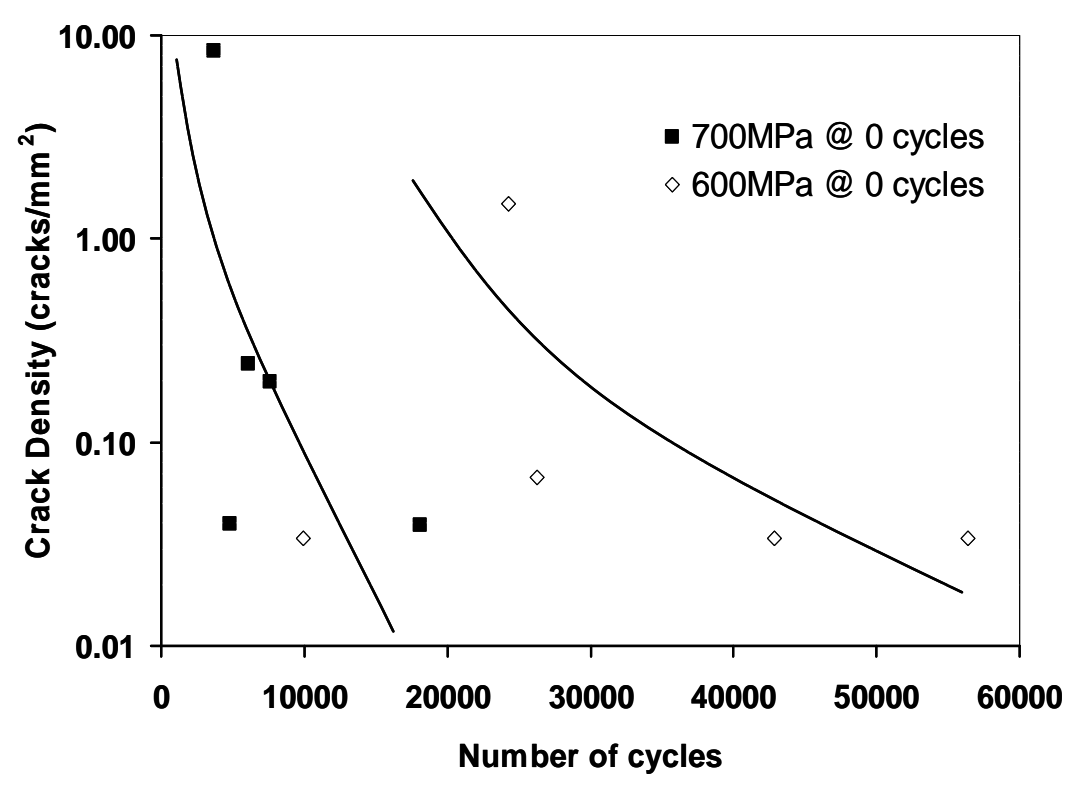

Fig. 10 Extent of carbide cracking on initial loading for short fatigue crack specimens correlated with final fatigue life. 

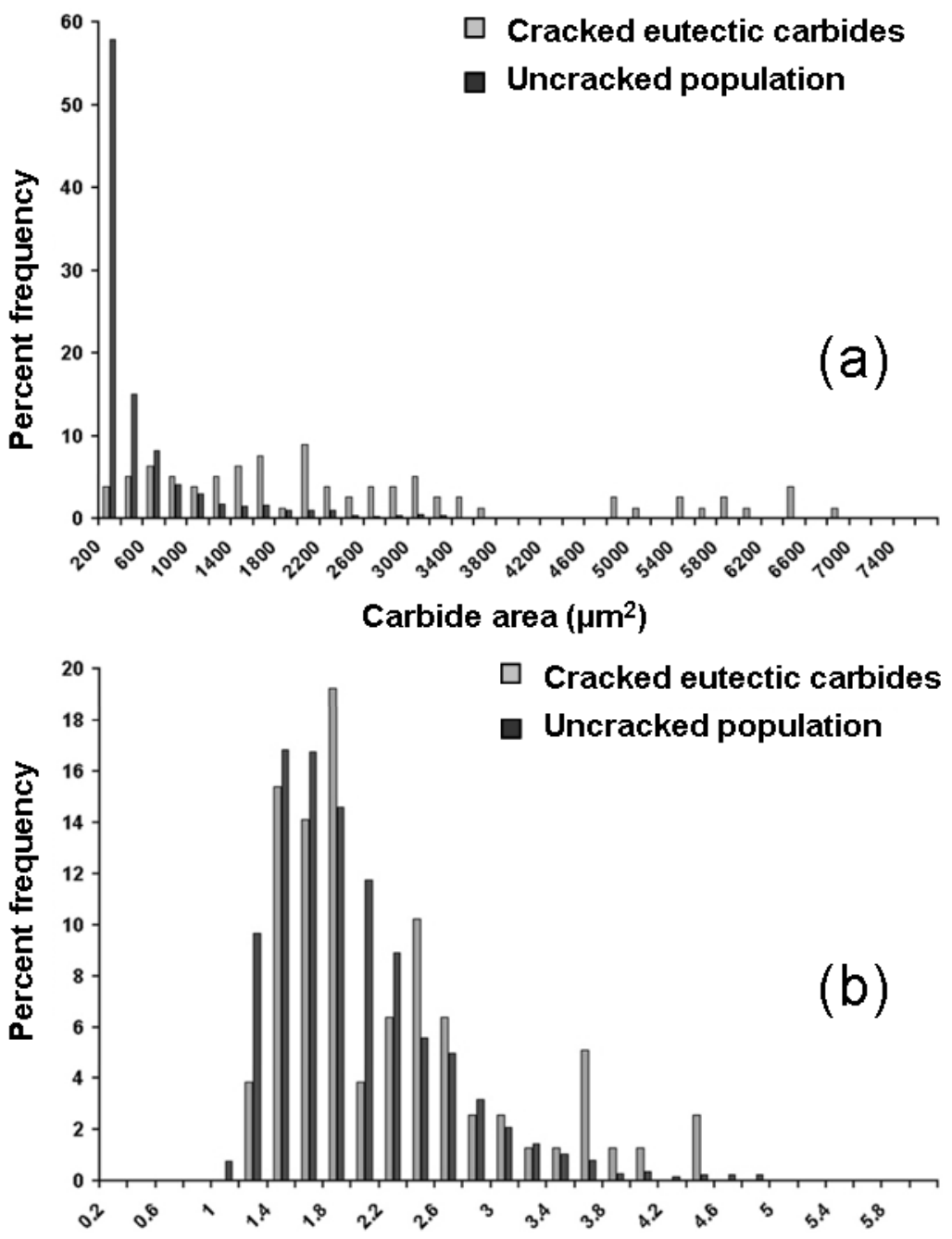

Carbide aspect ratio

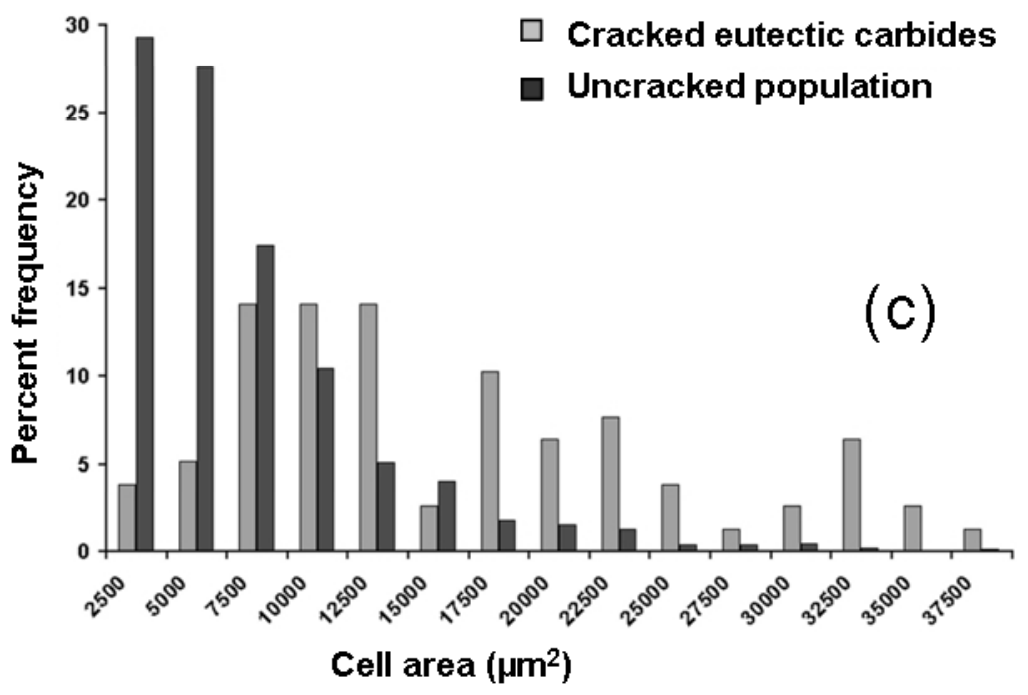

37 

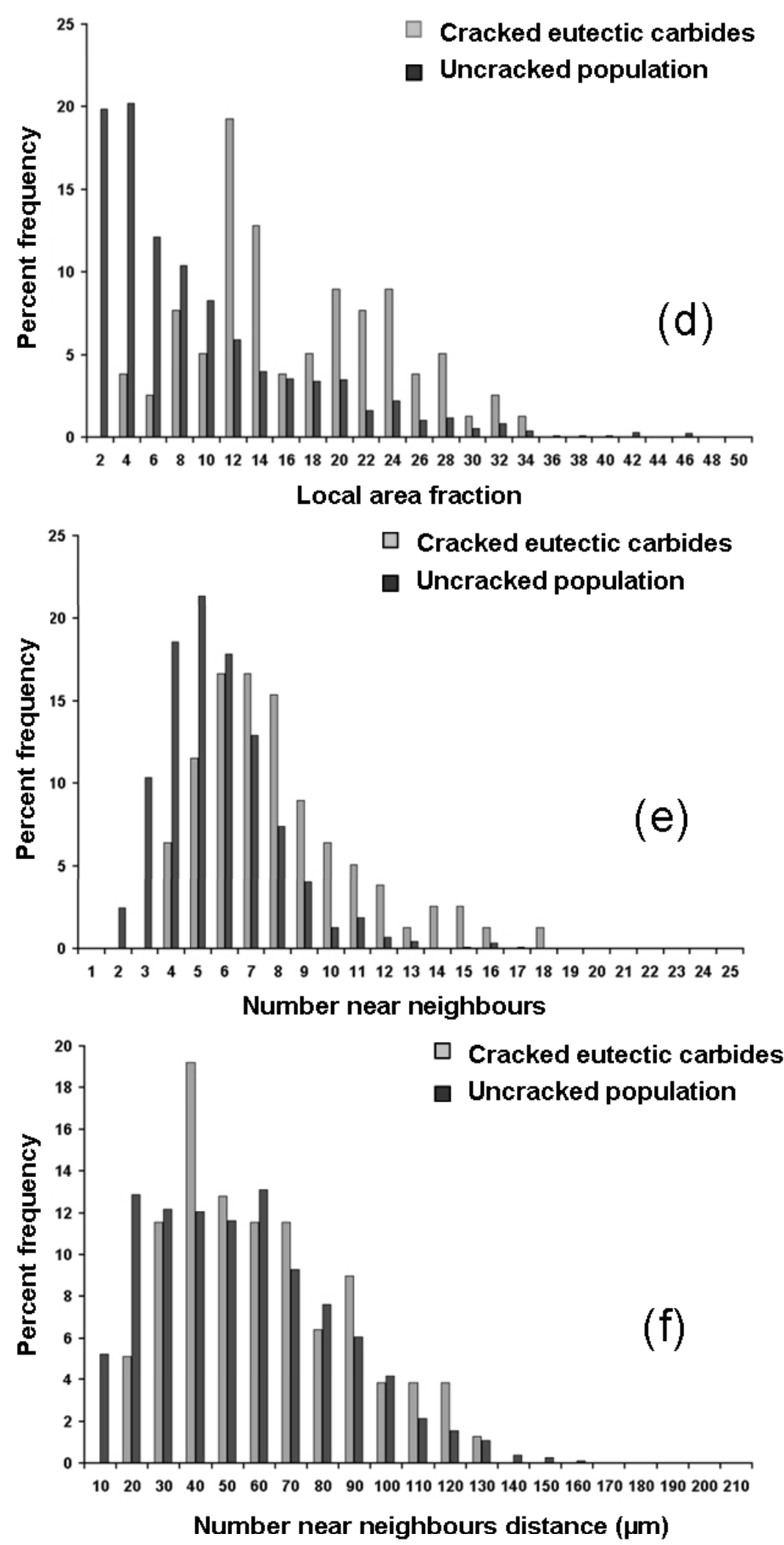

Fig. 11. Characterisation of crack initiating eutectic carbides. 

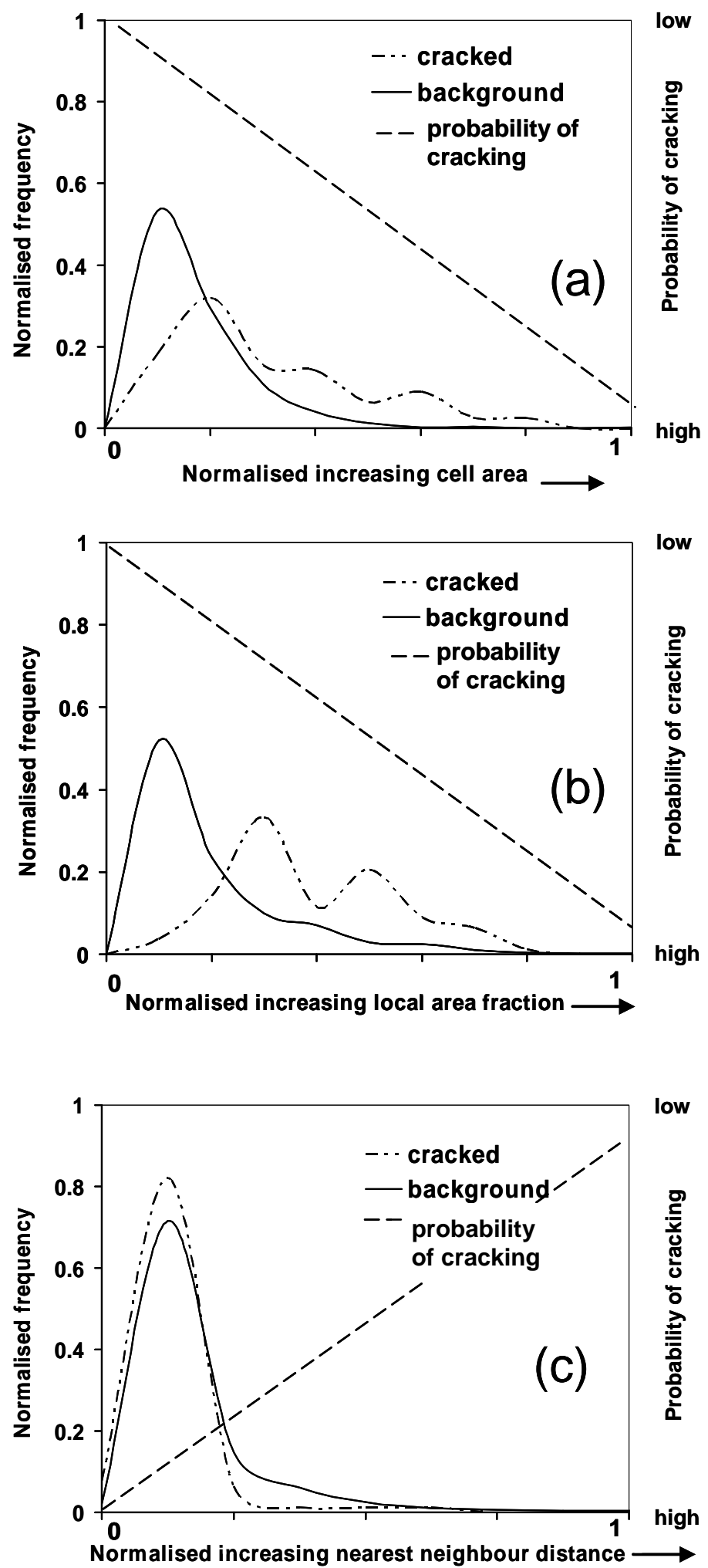

Fig. 12 SUPANOVA generated univariate terms for classification of crack initiating carbides in the short fatigue crack specimens with associated data-spread. (a) Cell area; (b) Local area fraction; (c) Nearest neighbour distance. 

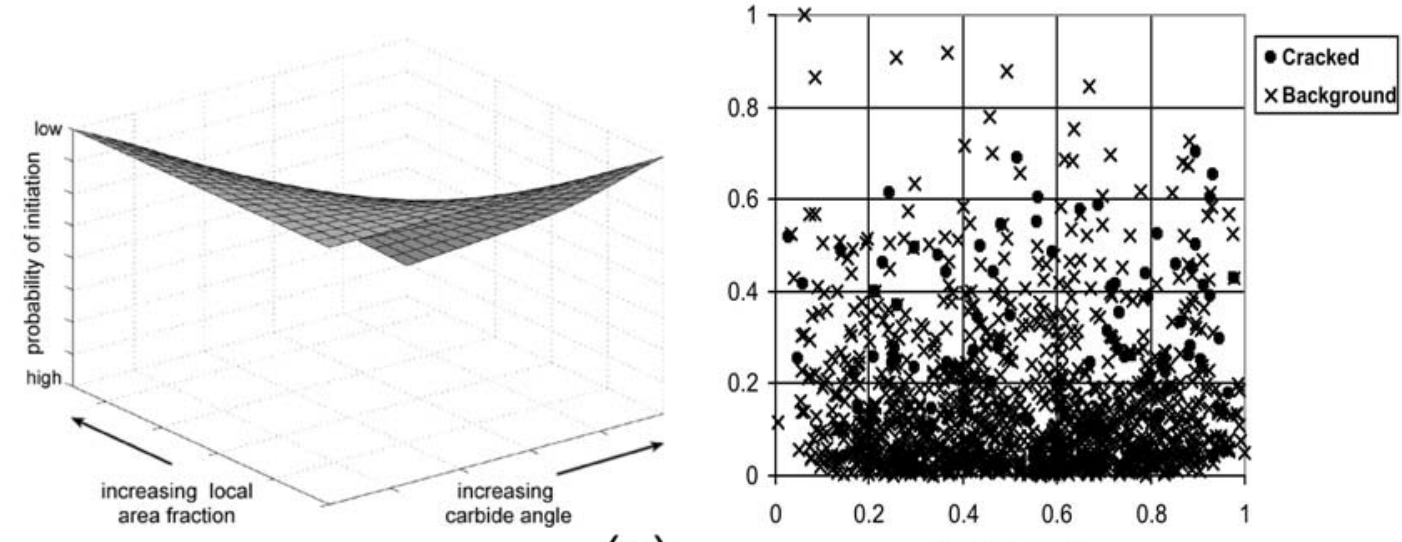

(a)

Carhirie ancile
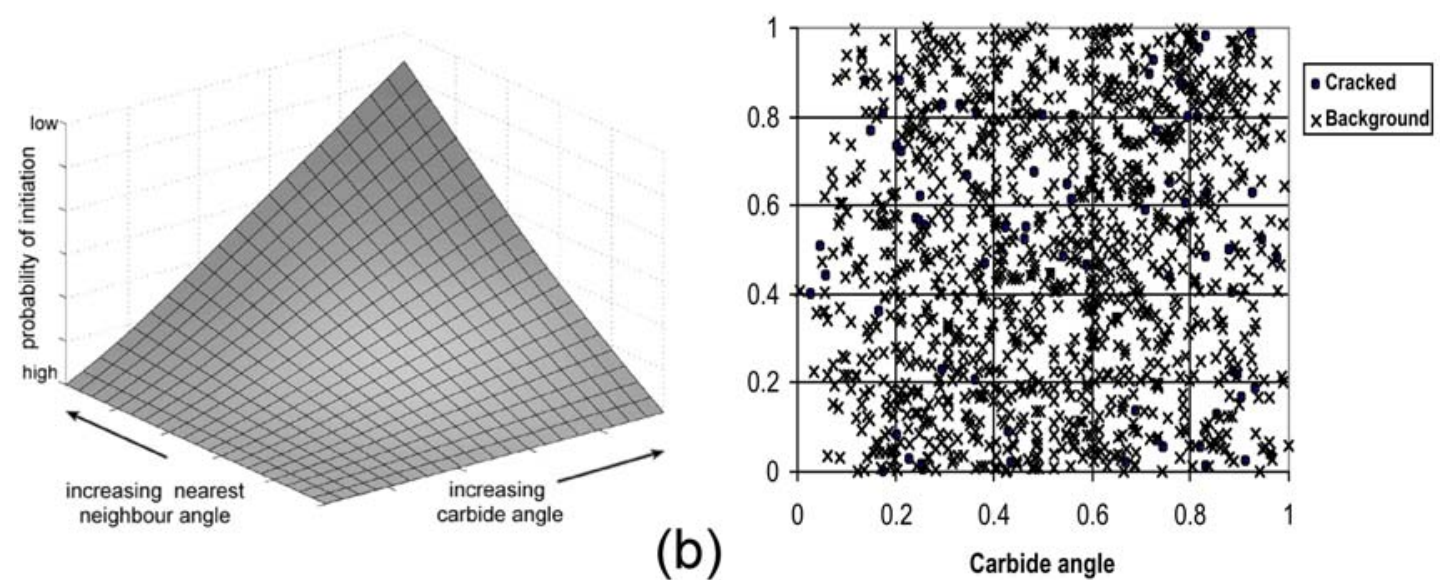

Fig. 13 SUPANOVA generated bivariate terms for classification of crack initiating carbides in the short fatigue crack specimens. Spread of data for each term shown alongside. (a) Carbide angle vs. local area fraction; (b) Carbide angle vs. nearest neighbour angle. 

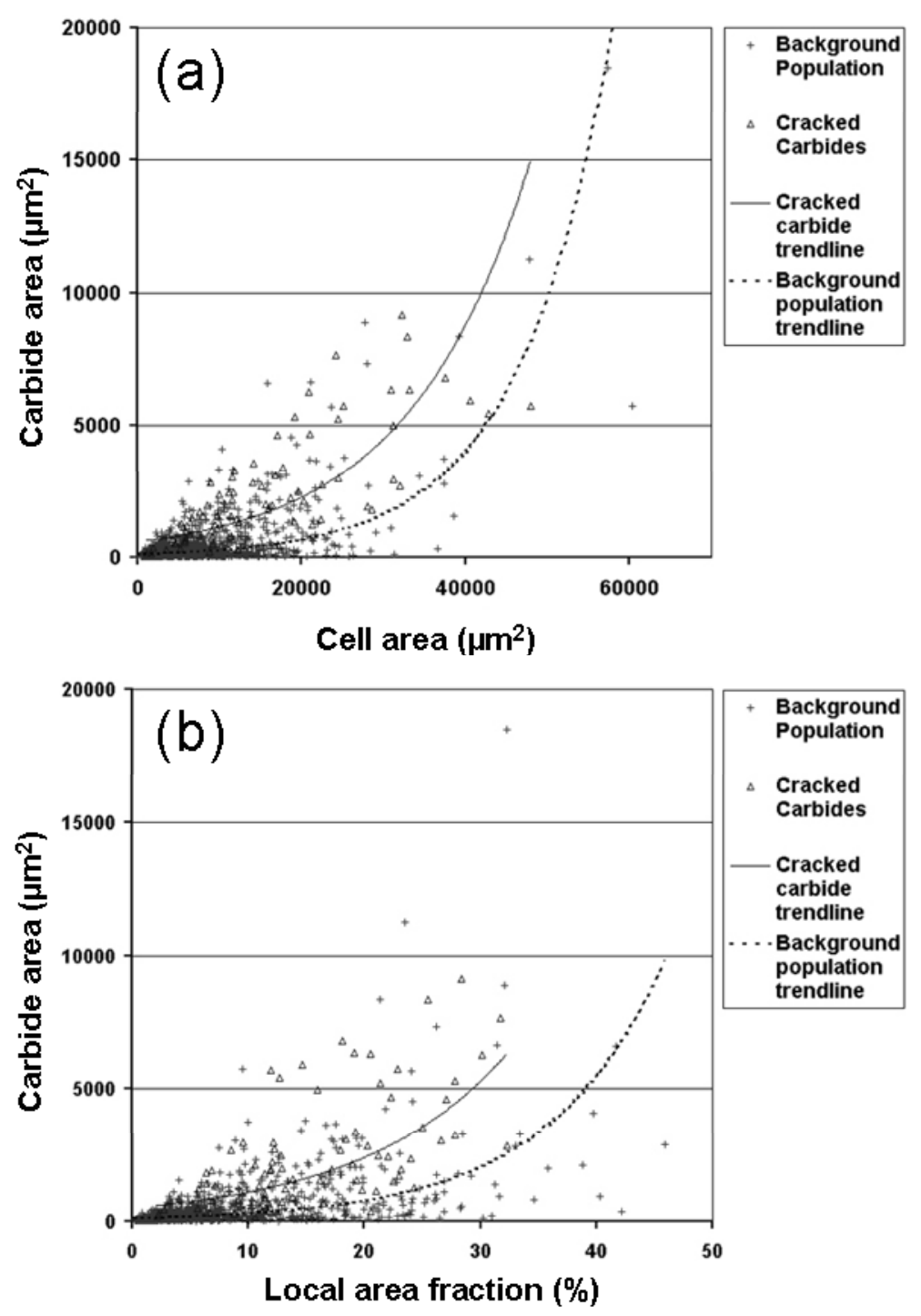

Fig. 14 Comparison of carbide area and (a) cell area; (b) local area fraction, used for SUPANOVA classification of cracked carbides. 